\section{Diversidad cultural y pueblos indígenas: una mirada sobre las TIC}

Ivana Mihal ${ }^{\star} y$ Marina Matarrese ${ }^{* *}$

Resumen: Las problemáticas concernientes a los pueblos indígenas no han dejado de constituir hasta el presente tópicos en las preocupaciones antropológicas. El artículo trata, desde esa perspectiva, precisamente de la relación entre pueblos indígenas y las tecnologías de la información y la comunicación (TIC). Para ello, a partir del análisis de las políticas indigenistas en materia de TIC y particularmente de la Ley $\mathrm{N}^{\circ} 26.522 / 09$, Ley de Servicios de Comunicación Audiovisual de Argentina (LSCA), se indagará cuáles son las simbolizaciones y representaciones subyacentes con respecto a los pueblos indígenas que permean dichas políticas.

Palabras clave: Diversidad cultural - Pueblos indígenas - Tecnologías de la Información y la comunicación - Ley de Servicios de Comunicación Audiovisual.

[Resúmenes en francés, inglés y portugués en las páginas 192-193]

${ }^{*}$ Investigadora Adjunta del Consejo Nacional de Investigaciones Científicas y Técnicas -CONICET- con lugar de trabajo en la Escuela de Humanidades de la Universidad Nacional de San Martín -UNSAM-. Doctora en Filosofía y Letras, área Antropología (Universidad de Buenos Aires -UBA-, Facultad de Filosofía y Letras). Docente del Doctorado en Diseño de la Facultad de Diseño y Comunicación de la Universidad de Palermo.

${ }^{(*)}$ Investigadora Asistente del Consejo Nacional de Investigaciones Científicas y Técnicas -CONICET- con lugar de trabajo en la Sección Etnología de la Facultad de Filosofía y Letras de la Universidad de Buenos Aires -UBA- Doctora en Filosofía y Letras, área Antropología -Universidad de Buenos Aires, Facultad de Filosofía y Letras-. Docente del Doctorado en Diseño y Coordinadora del Programa de Investigación DC de la Facultad de Diseño y Comunicación de la Universidad de Palermo. Profesora Titular de la Universidad Nacional de Lomas de Zamora.

\title{
Introducción
}

A partir de la mirada de la antropología, el presente trabajo ${ }^{1}$ gira en torno a la relación de las tecnologías de la información y la comunicación (TIC) y la diversidad cultural estudiada particularmente con respecto a los pueblos indígenas de Argentina. 
Si bien es sabido que en los últimos años se ha reconocido -por medio de convenciones y declaraciones internacionales y adherencias de los Estados nacionales ${ }^{2}-$ que la diversidad cultural implica el reconocimiento de las diferencias étnicas, de género, lingüísticas, entre otras, pero fundamentalmente de las desigualdades socioeconómicas y de las diferentes formas de asimetría y dominación (García Canclini, 2009; Barbero, 2009). Dichas desigualdades y asimetría si bien son registradas en algunos casos y hasta cuentan con legislación al respecto, perduran y se renuevan en la actualidad formando forman parte de temporalidades pasadas y presentes, inclusive cuando el objeto de estudio son las TIC, y mucho más cuando se trata de pueblos indígenas.

El artículo analiza la Ley de Servicios de Comunicación Audiovisual (LSCA) ${ }^{3} \mathrm{~N}^{\circ} 26.522$, sancionada y promulgada el 10 de octubre del año 2009 y modificada por Decreto $\mathrm{N}^{\circ} 267$ de 2015, en su articulación con los pueblos indígenas. Cabe aclarar que el presente trabajo se concentrará en ciertos puntos significativos del articulado de esta normativa y no en las dificultades de su implementación ni en las posteriores modificaciones del mencionado Decreto. Algunas de las problemáticas identificadas en esta ley exceden propiamente el campo de las TIC para inscribirse en cuestiones más profundas respecto a la representación, simbolización y agentividad de los pueblos indígenas.

Se han identificado tres ejes que guían el recorrido de este texto a partir de un conjunto de tópicos prioritarios que posibilitan acotar la complejidad de esta problemática. En el primer eje, se dará cuenta sucintamente de las contribuciones de la antropología para pensar la estética desde parámetros valorativos no circunscriptos exclusivamente al arte occidental. En el segundo eje, se estudiará la representación de los pueblos indígenas en la construcción del Estado-Nación y cómo dicha representación repica en un imaginario de población argentina blanca y europea que persiste e involucra temporalidades pasadas que se imbrican hasta la actualidad. Por último, en el tercer eje se desarrollará el abordaje de la LSCA y la inclusión que esta propone de los pueblos indígenas.

\section{Eje 1. Problematizando la dimensión estética desde la diversidad cultural}

La diversidad humana está constituida por prácticas y concepciones cuyas subjetividades se encuentran atravesadas por diferentes temporalidades y estéticas, como ya reflexionara Lévi-Strauss (1955) en Tristes Trópicos. La antropología ha subrayado que la dimensión estética constituye un espacio potencial para acceder a nuevos sentidos acerca de la historia y la identidad de los pueblos indígenas, tema ineludible de análisis para los padres de la disciplina antropológica (Boas, 1927; Lévi-Strauss, 1958; 1969). Ahora bien, la estética ha sido poco explorada en las últimas décadas o bien relegada a un lugar marginal dentro del campo de estudios antropológicos, en particular por su inevitable vinculación a la lógica del campo artístico (Gow, 1996), así como el campo artístico desatiende frecuentemente la mirada de lo diverso y de otras expresiones y prácticas culturales.

Cuando se apela en este estudio al concepto de estética se procura diferenciarlo de otras categorías como las de arte y "arte no occidental" y siguiendo a Jacques Maquet (1999) se advierte que numerosos trabajos han empleado indistintamente los términos estética y arte, proyectando sobre este último el "locus estético" de la sociedad occidental a otras cul- 
turas. Asimismo, para el presente análisis se utiliza la categoría de estética destacando su potencial transcultural (Coote, 1992; Coote y Shelton, 1992; Maquet, 1999; Morphy, 1991, 1992; Sharman, 1997) y las relaciones de poder por las que están atravesadas y condicionadas las diversas expresiones estéticas (Morphy, 1992). Habida cuenta de esta propuesta conceptual la dimensión estética de la diversidad cultural deviene en un instrumento particularmente próspero.

Sin embargo, esta dimensión muchas veces es relegada cuando se analizan las experiencias vinculadas con las TIC. Precisamente pensar la dimensión estética en clave de diversidad cultural posibilita entender y cuestionar estereotipos y/o naturalizaciones con respecto a las minorías culturales y a los pueblos indígenas en particular como se verá en el siguiente apartado. Con antelación a las tecnologías digitales también era necesario desentrañar ciertas imágenes pre-establecidas respecto a las alteridades y a la diversidad cultural. Los modos en que se han representado tanto gráfica como discursivamente, y circulado, reproducido, y vuelto a circular sentidos y significaciones en el marco temporal de mediana duración ${ }^{4}$, no son nuevos pues la antropología, sobre todo -junto con otras ciencias sociales- se han encargado de desmontar en gran medida imágenes cargadas de prejuicios sobre la diversidad cultural (Ardèvol, 1998). Dichos prejuicios han contribuido a generar imágenes muchas veces descontextualizadas y atemporales en fotografías ${ }^{5}$, en cine, en manuales escolares ${ }^{6}$, y en otras expresiones artísticas que han operado como constructoras de subjetividades respecto a estos colectivos. Estas construcciones no son exclusivas de los pueblos indígenas sino también de otras pertenencias étnicas sobre las que se generan categorías sociales, atributos y valoraciones peyorativas. En este sentido, se entiende que el campo estético puede ser considerado como un campo de batalla en el que pugnan por tener lugar informaciones, conocimientos y sentidos que fueron acallados y silenciados por otros reportorios hegemónicos (Guerreiro, 2016).

Teniendo en cuenta lo expuesto, el Estado en tanto dispositivo con sus normativas, reglamentos y políticas indigenistas (Lenton, 2010) construye y reconfigura imágenes y representaciones acerca de las alteridades e inclusive de los pueblos indígenas. Asimismo, los pueblos indígenas en su instalación pública de demandas y derechos también se sitúan y construyen apelando a diversas imágenes de sí mismos en tanto parte de su agentividad y de sus estrategias políticas. Los pueblos indígenas en tanto minoría han sido tratados marginalmente por Estado-nación; y son ellos quienes mayor flexibilidad han mostrado para convivir con la diversidad, en su relación con distintas comunidades indígenas y noindígenas, tanto como al interactuar con lenguas dominantes; a ejercitar distintas formas asociativas, entre otras cuestiones. De este modo han ido construyendo históricamente distintas estrategias en el marco de la diversidad cultural y de la desigualdad socio económica para poder dar visibilizar sus demandas y reivindicaciones y principalmente constituirse como sujetos plenos de derecho. Estas representaciones de las minorías tensionan las hegemónicas y es sobre todo desde las que en los últimos años las TIC han contribuido a fomentar con mayor densidad, lo que se desarrollará en el segundo eje. 


\section{Eje 2. La representación de los pueblos indígenas en la construcción del Estado-Nación}

Según el último censo nacional, los pueblos indígenas constituyen el 3,4\% de la población (INDEC, 2010). La construcción discursiva y la presencia indígena en Argentina, tal como la han caracterizado Gordillo y Hirsch (2010) pueden entenderse como una "presencia ausente". Este país ha negado desde su discurso fundacional, y aún sigue muy presente el mismo, la presencia indígena. Sumado a lo antedicho ha desplegado campañas militares genocidas a fines del Siglo XIX tanto hacia el Gran Chaco (lñigo Carreras, 1983, 1984; Trinchero, 2000) como a Pampa y Patagonia (Delrio, 2010; Lenton, 2010).

La construcción discursiva operada desde los múltiples dispositivos estatales de la mano de producciones científicas y literarias ${ }^{7}$ ha coadyuvado a delinear discursos performativos entre los cuales destacan lo que Pablo Wright (1997) ha denominado la narrativa del desierto, reforzando en primer lugar la ausencia. En segundo lugar, el remanente indígena era representado en tanto sujetos indómitos y pasibles de exterminio y/o en caso de que fuera necesario de conversión y disciplinamiento civilizatorio. Como sostiene Pacheco de Oliveira (2006) ciertas palabras jalonan imágenes inequívocas que orientan el pensamiento y la acción pero que no dejan de ser constructos. Como la palabra desierto, ocurre con el vocablo "indios', que [...] evoca unos jirones de humanidad dotados de una tecnología rudimentaria, viviendo en pequeños grupos y aislados en las selvas, condenados a desaparecer frente al avance de una modernización cada vez más inexorable y globalizada" (Pacheco de Oliveira, 2006, p. 7).

Ese constructo funcionó en sintonía con el mito del desierto verde (Wright, 1997) en el Gran Chaco y al desierto libre de personas dispuestas a darle la bienvenida a la civilización europea y blanca una vez acaecida la limpieza étnica en el sur argentino. Las condiciones que habilitaron dichos dispositivos discursivos invisibilizaron y a su vez visibilizaron porciones y versiones de realidad (De Certeau, 1996). Discursos que tuvieron y aún tienen efectos concretos, palabras que funcionaron entre las cosas y, muchas veces, fueron a la cabeza de los cuerpos, precipitando acciones y legitimando el estado de ellas (Rodríguez, 2010). En este marco, se forjó una imagen de Estado-Nación blanca y europea, como ya se dijo, cuyos habitantes vinieron de los barcos (Briones, 1998) quedando los indígenas en tanto otro interno invisibilizado dentro de este Estado. Este conjunto de representaciones los instalaron en un locus de inmutabilidad y en una cómoda lejanía espacio-temporal que Anderman (2000) define como paleontologización del otro.

Es en este marco que algunos diacríticos (Barth, 1969) tales como la vestimenta, el lenguaje, $\mathrm{u}$ otros aspectos de los pueblos indígenas propios de los siglos XIX y principios del $\mathrm{XX}$ han quedado arraigados y aún configuran sentidos. En esa lógica los indígenas todavía siguen asociados al pasado, a la ruralidad, a la pobreza, al analfabetismo y a lo comunal (Navarro Smith, 2012). Habida cuenta de lo antedicho y a fin de poner en relieve son elocuentes dos imágenes extraídas de un video del personaje llamado Zamba en la "La Asombrosa Excursión a los Pueblos Originarios" desarrollado por el Canal Paka Paka, una señal pública surgida en 2010, orientada al público infantil y dependiente del por entonces Ministerio de Educación. 
A través de dicho video se dan a conocer algunos pueblos de nuestro país, particularmente Mapuche (en la propia vivienda realizando trabajos artesanales -Ver Figura 1), y Guaraní (en situaciones de ceremonial con vestimentas para la celebración que se le cuenta al personaje -Ver Figura 2). Sin embargo en ningún momento del desarrollo del contenido del citado video se incorporan situaciones también actuales protagonizadas en las grandes urbes siendo que el último Censo Nacional de la República Argentina (INDEC, 2010) arrojó que la población indígena predominantemente vive en áreas urbanas ${ }^{8}$. Es decir, sigue vigente la concepción de que para reconocer y reconocerse como indígena es necesario tener una pluma en la cabeza en tanto diacrítico por excelencia o vivir en el campo cual portación cosificada de cultura que se pierde con la migración o las transformaciones en los atavíos (Jackson, 1995; Ramos y Delrio, 2005). Estas imágenes se sostienen en otras representaciones propuestas por el canal cuya temporalidad indígena se construye en dos hitos históricos que son la conquista de América (1492) y la Reforma de la Constitución Nacional (1994). De este modo se omite la relación del Estado-Nación argentino con los pueblos indígenas desde su constitución. En efecto se oculta una historia local de genocidio e invisibilización perpetrado por el propio Estado-Nación tal como lo constituyó la denominada Conquista del Desierto (1878). Cabe consignar que, con todo este contenido ha sido el único que incluyó en canales con contenido infantil y de manera animada a los pueblos indígenas como parte de su programación.

Es cuestionable la utilización de estos diacríticos para cosificar y esencializar a estos pueblos, no obstante en ciertas prácticas y simbolizaciones los utilizan. Estos usos pueden ser estratégicos, políticos, rituales o cotidianos. Estos modos de dar cuenta de ciertas marcas identitarias estratégicamente, funcionan como diacríticos a fin de instalar o lograr mayor repercusión de sus demandas en la esfera pública (Cardín, 2013). No obstante dichos usos no los definen per se y referenciar su identidad en relación con ellos es restringirla no dando lugar a transformaciones socio históricas y culturales de todo grupo social. Asimismo, estos diacríticos muchas veces ante ciertos sectores sociales los obtura en la obtención plena de derechos poniendo de manifiesto una tensión no resuelta con respecto a la sociedad dominante.

Parte de toda esta complejidad representacional, identitaria y presupuestos estudiados en este eje, inciden a la hora de diseñar políticas indigenistas inclusivas y en tal sentido es menester un análisis crítico de las mismas tal como el a continuación expuesto.

\section{Eje 3. Pueblos indígenas en la LSCA}

A fin de marcar un punto de partida analítico y siempre arbitrario con respecto a las políticas indigenistas, se consigna el retorno a la democracia en 1983 y más fuertemente a la década de 1990 como un momento en el que comenzó un proceso de reconocimiento de los pueblos indígenas y en el que colaboró la presión de dirigentes y militantes de organizaciones creadas entre 1970 y 1980, cuyo corolario ha sido la sanción de la Ley Nacional 23.302/85 sobre Política Indígena y Apoyo a las Comunidades Indígenas y la Reforma en 1994 de la Constitución Nacional reconociendo la preexistencia étnica y cultural de estos pueblos (art. 75, inc. 17). 


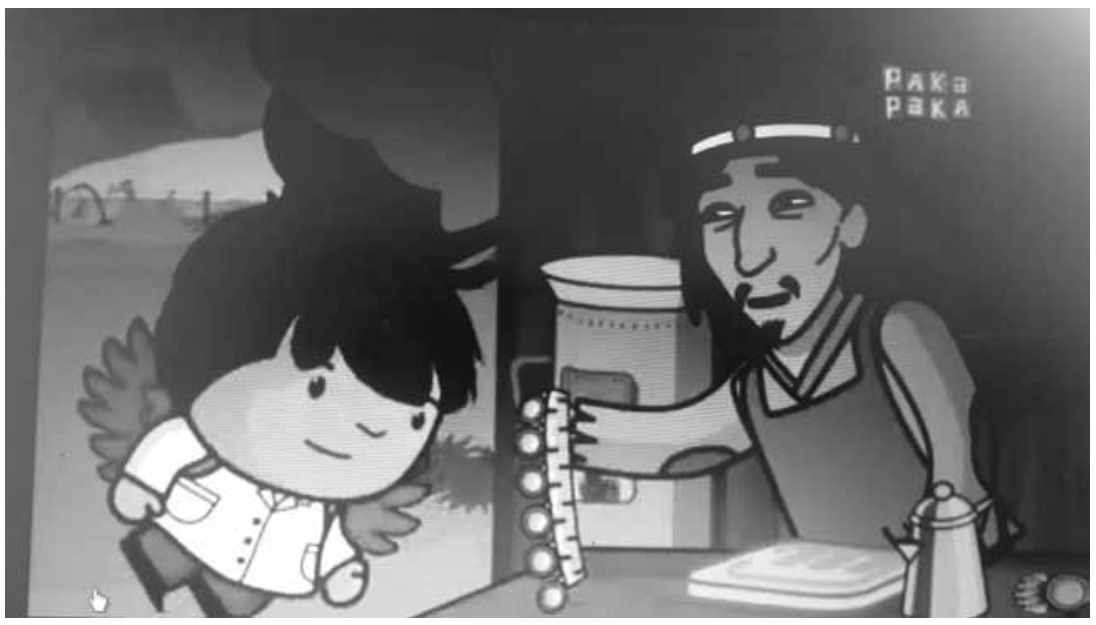

Figura 1. Fuente: Canal Paka Paka. http://www.pakapaka.gob.ar/videos/128025

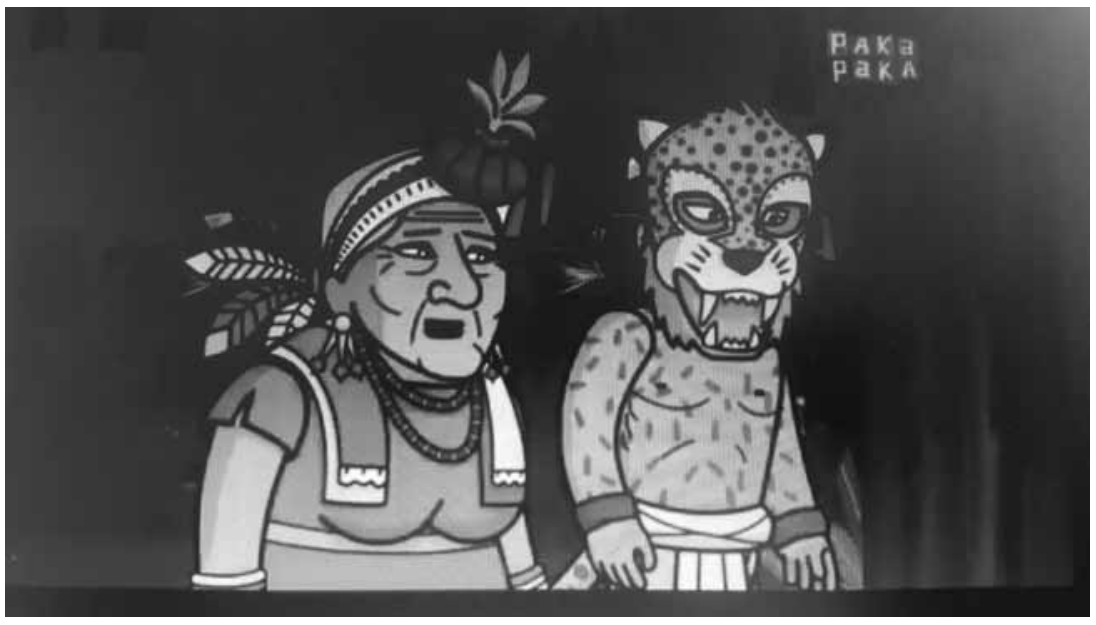

Figura 2. Fuente: Canal Paka Paka. http://www.pakapaka.gob.ar/videos/128025 
Cabe hacer una distinción conceptual, siguiendo a Lenton (2010), en nuestro país existen políticas indigenistas que son aquellas referidas a los pueblos indígenas en planes, programas, leyes, normativa general e instituciones, entre otros. Por otro, también existe política indígena en tanto política de representación y estrategias de participación y /o autonomización de las organizaciones de militancia y/o colectivos de pertenencia de dichos pueblos (Lenton, 2010). Como se verá, la LSCA es un claro ejemplo en el que se conjuga esta disquisición conceptual.

La LSCA fue sancionada y promulgada el 10 de octubre de 2009, sin embargo fue el resultado de un proceso iniciado muchos años antes y del cual participaron, entre otros actores movimientos sociales que reivindicaban y demandaban la democratización de los medios en el país (Kejval, 2014). Las organizaciones indígenas fueron uno de los actores que asumieron esta demanda como propia, por ello de acuerdo con Lenton (2010) es posible considerar dicha demanda como parte de la política indígena. Ahora bien, en ese proceso ${ }^{9}$ en el cual derivó la instauración de la LSCA interesa destacar la Coalición por una Radiodifusión Democrática -la que en 2004 articuló a universidades, intelectuales, gremios, organismos de derechos humanos, entidades gestoras de derechos, etc.-, y entre ellos, a los pueblos indígenas que ya venían demandado espacios concretos en los canales de comunicación y en sus propios idiomas.

Esta Coalición consensuó un documento denominado "Veintiún puntos básicos por el derecho a la comunicación" algunos de cuyos aportes fueron recuperados en el 2008 cuando el entonces gobierno nacional decide poner como tema de agenda pública el tratamiento de la ley de medios (Kejval, 2014). Para su construcción amplía como interlocutores válidos a organizaciones de distintos pueblos indígenas (OCASTAFE, Asamblea Pueblo Guaraní, Consejo de Cacique Guaraní, Federación Pilagá, Pueblo Kolla de la Puna, InterToba, Consejo de la Nación Tonocote Llutqui, Kereimba Iyambae, Unión de los Pueblos de la Nación Diaguita, Confederación Mapuche Neuquina, ONPIA, Coordinadora Parlamento Mapuche Río Negro, Mesa de Organización de Pueblos Originarios de Almirante Brown, Malal Pincheira de Mendoza, Comunidad Huarpe Guentota, Organización Territorial Mapuche Tehuelche de Pueblos Originarios Santa Cruz, Organización Ranquel Mapuche de La Pampa, Organización del Pueblo Guaraní) y a diferentes entidades, sectores y personalidades que participaron de los encuentros en los que se debatieron los alcances y contenidos de la ley. Es en este sentido que la LSCA en tanto involucró a los pueblos indígenas se constituyó también como una política indigenista (Lenton, 2010) que se hizo eco de las demandas y reivindicaciones de derechos a la comunicación de la política indígena. La LSCA tuvo como objetivo regular en todo el territorio nacional los servicios de comunicación audiovisual mediante "...el desarrollo de mecanismos destinados a la promoción, desconcentración y fomento de la competencia con fines de abaratamiento, democratización y universalización del aprovechamiento de las nuevas tecnologías de la información y la comunicación" (art. 1). Si se consideran que los medios de comunicación son una de las principales industrias relacionadas con bienes y servicios simbólicos y de entretenimiento y que es a través de ellos que se configuran imaginarios, valorizaciones de las identidades que conforman nuestro país así como la representación de las alteridades, los medios también generan consensos y disensos de gran llegada al público masivo acerca de las disputas de sentido y de poder que dichas configuraciones implican. Los medios, 
de este modo, constituyen "escenarios fundamentales donde se legitiman ideas, sujetos y los asuntos públicos a ser debatidos y atendidos" (Kejval, 2014, p. 93). En esa misma línea retórica Lázzaro (2017) plantea que la ley apuntaba no sólo a desmantelar la hegemonía multimediática de pocos actores, de manera de incidir en la desigual concentración de los medios, sino también a favorecer la protección, producción y circulación de contenidos culturales propios como se enfatizaba de la mano del acceso y la generación de contenidos que fomentaran la diversidad cultural del país. Un ejemplo de ello es que la LSCA incorporó, como parte de la programación, que se pueda tener contenido en el idioma original de los pueblos indígenas (art. 9).

Por último, y como parte de dicho proceso de ampliar la pluralidad, la normativa incorpora la creación de un Consejo Federal de Comunicación Audiovisual (art. 16) con 1 integrante de cada jurisdicción del país y del Gobierno de la Ciudad Autónoma de Buenos Aires, 3 representantes de los prestadores privados de carácter comercial, 3 de los prestadores sin fines de lucro; 1 de las emisoras de las universidades nacionales; 1 de las universidades nacionales con facultades o carreras de comunicación; 1 de los medios públicos de todos los ámbitos y jurisdicciones; 3 representantes de los sindicatos de trabajadores de los medios, 1 representante de las sociedades gestoras de derechos y 1 representante de los pueblos originarios reconocidos ante el Instituto Nacional de Asuntos Indígenas (INAI). De este modo aunque en menor grado de representatividad se los involucra como parte de una minoría representativa en términos de derechos a la comunicación.

Si se tiene en cuenta el articulado completo de la normativa se pueden resaltar otros aspectos que están contemplados en la LSCA y que responden a criterios de operatividad o ejecución concreta de la ley, los que presentan diversas dificultades (Kejval, 2014). Sin embargo, en vinculación con los objetivos de este eje cabe consignar que la LSCA constituyó una política pública indigenista inclusiva que consideró algunas de las demandas de la política indígena, no obstante dicha inclusión estuvo referenciada primordialmente en la participación en ciertos espacios concretos de la gestión pública, en los debates de los contenidos de la ley y en lo lingüístico.

\section{Reflexiones finales}

En este artículo se acotó, a partir de tres ejes de análisis, el abanico de cuestionamientos posibles en una temática que se mantiene vigente en relación con las TIC y los pueblos indígenas. En el primer eje, tal como se ha visto, la dimensión estética se constituye a través de dimensiones de poder en las que frecuentemente las minorías étnicas y puntualmente los pueblos indígenas de nuestro país han sido corridos de la escena analítica. En este sentido, la variable estética es un aspecto a partir del cual se ponen en relieve determinadas desigualdades tanto como se visibilizan ciertos diacríticos identitarios. Estas marcas operan en una doble dimensión, por un lado imprimen y reivindican determinadas pertenencias étnicas desde la que se demandan la efectivización de derechos; y por el otro, esas mismas marcas reafirman determinados prejuicios con respecto a estos grupos arraigados en el sentido común. 
En efecto esa invisibilización y denostación para con los pueblos indígenas se remonta, tal como se vio en el segundo eje, en la construcción del Estado Nación de la mano de una idea de una población europea y blanca y se perpetúa en la actualidad a través de producciones vinculadas a los medios de comunicación que raras veces los incluyen en sus contenidos y en la participación de su programación y cuando esto se hace es en clave de exotización y acentuando un modo de vida anclado en la ruralidad y en rituales, no tanto en la vida cotidiana de las grandes urbes.

La LSCA posibilitó, como se mostró en el tercer eje, dar cabida a que los programas radiales o televisivos puedan ser en los idiomas de los propios pueblos indígenas cuanto la participación a través de una instancia, como es el Consejo Federal de Comunicación Audiovisual. Esto último resulta particularmente significativo, dado que la participación de espacios promovidos por el Estado de temas que los implicaran ha sido tanto un dispositivo estatal como una demanda indígena; lo cual ha llevado a que sea considerada en este artículo como una política indigenista y una política indígena (Lenton, 2010) en una esfera en que se entrecruzan la estética, las TIC y los pueblos indígenas. Pero también en relación con estos pueblos ha sido una ley que ha posibilitado en parte considerar la incorporación de una minoría como los pueblos indígenas en ámbitos de gestión pública, lo cual aunque muchas veces suele ser reconocida suele ser bastante distante a la hora de ponerse en práctica (Mihal, 2017). Cabe subrayar que estos distintos aspectos se relacionan con la concreción de derechos, pues como sostiene García Canclini (2009) es necesario inscribir a los medios y a las TIC tanto como parte de los derechos culturales como de los derechos conectivos, e incluir la participación de los distintos grupos sociales en las comunicaciones. Es esto último, en gran medida, lo que ha favorecido que la LSCA continué siendo una normativa -que aún con sus dificultades en su implementación y contenidos- haya sentado precedentes en tanto posibilitó valorizar a los pueblos indígenas a través de su consideración en el articulado.

\section{Notas}

1. Este artículo deviene de una investigación más amplia en el marco de un Proyecto de Investigación Plurianual (PIP N²0150100829, 2015-2017) sobre "Tecnologías de la información y la comunicación y pueblos indígenas: políticas de inclusión digital”, CONICET. Se relaciona asimismo con cuestiones que derivan de la labor docente de ambas autoras en el Doctorado de Diseño de la Facultad de Diseño y Comunicación, UP.

2. Principalmente con la aprobación de la Convención sobre la Promoción y Protección de la Diversidad y Expresiones culturales en la $33^{\circ}$ Conferencia General de la Unesco (París, 2005).

3. Si bien la LSCA tuvo como abordaje primordial a los medios de comunicación, de algún modo incluye a las TIC dado que lo digital y los medios cada vez confluyen más. Puntualmente, la Ley N² 27078/14 Argentina Digital estaba orientada a las TIC. Se ha definido, sin embargo, incorporar el análisis de cierto articulado de la LSCA porque uno de los aspectos a explorar en el estudio en el que se enmarca dicho artículo (PIP №20150100829), 
ha sido el de lineamientos y acciones de carácter inclusivo de los pueblos indígenas, y precisamente la ley los incorpora.

4. Esta temporalidad de mediana duración responde más a una disciplina histórica (Braudel, 1991; Ginsburg, 1976; Lefebvre, 1974)

5. Como han señalado Martínez y Tamagno (2006), detrás de la elección de la presentación de los indígenas en fotografías que los ubican como "objetos" existen relaciones sociales que muestran la violencia. Asimismo valiosos estudios sobre las fotografías del Gran Chaco han sido publicados por Mariana Giordano (2005; 2016 a y b).

6. A modo ilustrativo, se ha analizado a partir del material escolar, la construcción de los pueblos indígenas en la provincia de Formosa como seres que pertenecen "al monte", en un estado más próximo a la naturaleza indómita y en tanto tal remanentes de un pasado lejano y poco cotidiano a la realidad del ciudadano formoseño (Matarrese, 2013).

7. La narrativa imbuida de ideas del evolucionismo y del determinismo geográfico, estuvo basada en una lógica opositiva entre el desierto verde sobre el cual se asentaba la naturaleza expresada en el monte y los indígenas (caracterizados por el nomadismo y la desnudez) y la territorialidad estatal representada en fortines, ciudades, picadas, caminos, misiones, colonias, ingenios, fuerzas militares y pobladores/ciudadanos que condensaban los beneficios del progreso y la civilización (Matarrese, 2013).

8. Para un análisis más detallado de los datos desagregados por provincias que consigna el Censo Nacional de Población, Hogares y Viviendas (2010) ver: https://www.indec.gob. ar/nivel4_default.asp?id_tema_1=2\&id_tema_2=21\&id_tema_3=99

9. Se sugiere para una mayor profundidad del proceso previo ver Kejval (2014).

\section{Lista de referencias bibliográficas}

Anderman, J. (2000). Mapas de poder. Una arqueología literaria del espacio argentino, Rosario: Beatriz Viterbo.

Ardèvol, E. (1998). "Por una antropología de la mirada: etnografía, representación y construcción de datos audiovisuales". Revista de Dialectología y Tradiciones Populares, vol. LIII, No 2, p. 217-240.

Barbero, J. (2009). “Desafios políticos da diversidade”. Revista Observatório Itaú Cultural / OIC, $\mathrm{N}^{\circ}$ 8, abr.-jun., p. 153-159.

Barth, F. (1969). Los grupos étnicos y sus fronteras. México: Fondo de Cultura Económica.

Boas, F. (1927). Primitive Art. New York: Dover Publications.

Braudel, F. (1991). Escritos sobre la Historia. México D.F.: Fondo de Cultura Económica.

Briones, C. (1998). La alteridad del Cuarto Mundo. Una deconstrucción Antropológica de la diferencia. Buenos Aires: Ediciones del Sol.

Cardín, L. (2013). “Construcciones en disputa sobre la identidad qom. La escenificación de las diferencias ante la Corte Suprema de Justicia de la Nación”. En: Tola, F., C. Medrano y L. Cardín (comp). Gran Chaco. Ontologías poder, afectividad. Buenos Aires: Rumbo Sur. p. 361-384. 
Coote, J. (1992). "Marvels of Everyday Vision": The Anthropology of Aesthetics and the Cattle Keeping Nilotes. En: Coote, J.; Shelton, A. (comps.). Anthropology, Art and Aesthetics. Oxford: Clarendon Press. p. 245-273.

Coote, J. y Shelton, A. (1992). Anthropology, Art and Aesthetics. Oxford: Clarendon Press.

De Certeau, M. (1996). La invención de lo cotidiano 1. El oficio de la Historia. México: Editorial Iberoamericana.

Delrio, W. (2010). “El genocidio indígena y los silencios historiográficos". En: Osvaldo Bayer (coord.) Historia de la Crueldad Argentina. p. 67-76. Buenos Aires: RIGPI.

García Canclini, N. (2009). “Diversidade e direitos na interculturalidade global”. Revista Observatório Itaú Cultural / OIC, $\mathrm{N}^{\circ}$ 8, abr.-jun., p. 143-152.

Ginsburg, C. (1976). El queso y los gusanos. El cosmos de un molinero del siglo XVI. Turín: Einaudi.

Giordano, M. (2005). Discurso e imagen sobre el indígena chaqueño. La Plata: Ediciones Al Margen.

Giordano, M. (2016a). "Expediciones, fotografía y coleccionismo. Itinerancias visuales de un 'cultural broker' entre dos siglos." Revista de Indias; Madrid.

Giordano, M. (2016b). "Agencia y visualidad: las imágenes de la Guerra del Paraguay. De Cándido López a los videojuegos”. Folia Histórica del Nordeste; Resistencia; vol. 25, p. 119-132

Gordillo, G. y S. Hirsch (2010). “Presentación” En: Gordillo y Hirsch (comp.) Movilizaciones indígenas e identidades en disputa en la Argentina. p. 9-14. Buenos Aires: Crujía.

Gow, P. (1996). “Aesthetics is a cross-cultural category”. En: Ingold, T. (ed.), Key debates in anthropology. p. 249-293. London: Routledge.

Guerreiro, G. (2016). "Percepções do Atlântico - antropología estética, produção de conhecimento e antirracismo". Revista Observatório Itaú Cultural / OIC, $\mathrm{N}^{\circ}$ 21, nov. 2016-maio 2017, p. 112-127.

Instituto Nacional de Estadística y Censos (INDEC) (2010) Censo Nacional de Población, Hogares y Viviendas 2010. https://www.indec.gov.ar/nivel4_default.asp?id_ tema_1=2\&id_tema_2=41\&id_tema_3=135

lñigo Carreras, N. (1983). La colonización del Chaco. Buenos Aires: Centro Editor de América Latina.

lñigo Carreras, N. (1984). Campañas Militares y Clase obrera: Chaco, 1870-1930. Buenos Aires: Centro Editor de América Latina.

Jackson, J. (1995). Culture, Genuine and Spurious: the Politics of Indianness en the Vaupés, Colombia. American Ethnologist 22(1): 3-27.

Kejval, L. (2014). "Ley de Servicios de Comunicación Audiovisual: la institucionalización de la demanda por democratizar las comunicaciones". En Margulis, M. Urresti, M., Lewin, H. (comp.) Intervenir en la cultura. Más allá de las políticas culturales, p. 887-105. Buenos Aires: Ed. Biblos.

Lazzaro, L. (2017). “Un paisaje cultural amenazado por la uniformidad”. En: Piñón, F. (comp.) Indicadores Culturales 2015, p. 218-225. Sáenz Peña: UNTREF.

Lefebvre, H. (1974). "La producción del espacio”. Revista de Sociología, No. 3, p. 219-228.

Lenton, D. (2010). "Políticas del Estado indigenista y políticas de representación indígena: propuesta de análisis en torno al caso neuquino en tiempos de desarrollismo" Socieda- 
des de Paisajes áridos y semi-áridos. Revista Científica del Laboratorio de Arqueología y Etnohistoria de la Facultad de Ciencias Humanas, Universidad Nacional de Río Cuarto, II (2), 85-107. Río Cuarto.

Lévi-Strauss, C. (1968 [1958]). Antropología Estructural. Buenos Aires: EUDEBA.

Lévi-Strauss, C. (1969). Entrevistas con Georges Charbonnier: arte, lenguaje y etnología. México: Siglo XXI.

Lévi-Strauss, C. (1992 [1955]). Tristes Trópicos. Paidós: Barcelona.

Martínez, A. y Tamagno, L. (2006). "La naturalización de la violencia. Un análisis de fotografías antropométricas de principios del siglo XX". Cuadernos de Antropología Social, $\mathrm{N}^{\circ} 24$, dic., p. 93-112.

Matarrese, M. (2013). Las tramas ficcionales del proyecto de Nación en la construcción del "ser formoseño". Revista Question. Revista Especializada en Periodismo y Comunicación, Vol1, Nro 40, (octubre- diciembre 2013).p.334-346. http://perio.unlp.edu.ar/ojs/index. php/question/article/view/1964/1725.

Mihal, I. (2017). “Agenda en cultura: El I Congreso Argentino de Cultura”. En Calabre, L., et. al. (org.) Anais do VIII Seminário Internacional de Políticas Culturais, 23 a 26 de maio, p. 80-89. Rio de Janeiro: Fundação Casa de Rui Barbosa.

Maquet, J. (1999). La experiencia estética. Madrid: Celeste.

Morphy, H. (1991). Ancestral connections: Art and an aboriginal system of knowledge. Chicago: University of Chicago Press.

Morphy, H. (1992). "From Dull to Brillant: the Aesthetics of Spitirual Power among the Yolngu”. En: Coote, J. y A. Shelton (comps.) Anthropology, Art, and Aesthetics. p. 181-208. Oxford: Oxford University Press.

Navarro Smith, A. (2012). "Representación y antropología visual: videos y construcción de significados sobre lo cucapá”. Revista Chilena de Antropología Visual, № 20, diciembre, p. 79-105.

Ramos A. y Delrio, W. (2005). “Trayectorias de oposición. Los mapuches y tehuelches frente a la hegemonía en Chubut”. En: C. Briones (editora) Cartografías argentinas. Políticas indigenistas y formaciones provinciales de alteridad. Buenos Aires: Antropofagia. p. 79-119.

Rodríguez, F. (2010). Un desierto para la nación. La escritura del vacío. Buenos Aires: Eterna Cadencia Editora.

Sharman, R. (1997). "The Anthropology of Aesthetics: A cross-cultural approach". Journal of the anthropological society of Oxford XXVIII (2): 177-192.

Trinchero, H. (2000). Los dominios del demonio: Civilización y Barbarie en las fronteras de la Nación. El Chaco Central. Buenos Aires. EUDEBA.

Wright, P. (1997). “El desierto del Chaco: geografías de la alteridad y el estado”. En: Teruel, A.; Jerez, O. (Comps.) Pasado y Presente en el mundo postergado: Estudios de antropología, historia y arqueología del Chaco y Pedemonte Surandino. p. 35-56. Jujuy: Universidad Nacional de Jujuy.

Résumé : Les questions concernant les peuples indigènes sont jusqu'à présent restées des préoccupations anthropologiques. L'article traite précisément, dans une perspective an- 
thropologique, de la relation entre les peuples indigènes et les technologies de l'information et de la communication (TIC). À partir de l'analyse des politiques indigénistes dans le domaine des TIC et en particulier la loi sur les services de communication audiovisuelle de l'Argentine (loi n 26.522 / 09), on examinera à quels symboles et représentations sont associés les peuples indigènes qui soutiennent ces politiques.

Mots clés : Diversité culturelle - Peuples indiens - Technologies de l'information et de la communication - Loi des Services de Communication Audiovisuelle.

\begin{abstract}
Problems concerning indigenous peoples haven't ceased to constitute anthropological concern topics till now. This article analyze, from this perspective, the relationship between indigenous peoples and information and communication technologies (ICT). To do this, from the analysis of indigenist policies in the field of ICT and particularly the Law $N^{\circ}$ 26.522/09, Law of Audiovisual Communication Services of Argentina (LSCA), this study will research which are the underlying symbolizations and representations with respect to the indigenous peoples and that permeate these policies.
\end{abstract}

Keywords: Cultural diversity - Indigenous peoples - Information and communication technologies - Audiovisual Communication Services Law.

Resumo: Os problemas relativos aos povos indígenas não deixaram de constituir temas de preocupação antropológica até o presente. $\mathrm{O}$ artigo trata, daquela perspectiva, precisamente com a relação entre os povos indígenas e as tecnologias da informação e da comunicação (TIC). Para fazer isso, a partir da análise das políticas indigenistas no campo das TIC e particularmente da Lei no 26.522 / 09, Lei de Serviços de Comunicação Audiovisual da Argentina (LSCA), serão investigadas quais são as simbolizações e representações subjacentes em relação a os povos indígenas que permeiam essas políticas.

Palavras chave: Diversidade cultural - Povos indígenas - Tecnologias de informação e comunicação - Lei dos Serviços de Comunicação Audiovisual.

[Las traducciones de los abstracts al francés, inglés y portugués fueron supervisadas por el autor de cada artículo] 